\title{
Endogenous Dopamine Can Modulate Inhibition of Substantia Nigra Pars Reticulata Neurons Elicited by GABA Iontophoresis or Striatal Stimulation
}

\author{
B. L. Waszczak ${ }^{1}$ and J. R. Walters \\ Experimental Therapeutics Branch, National Institute of Neurological and Communicative Disorders and Stroke, \\ Bethesda, Maryland 20205
}

Previous reports from this laboratory have described an ability of iontophoretically applied dopamine to attenuate the inhibitory effects of iontophoresed GABA on neurons of the substantia nigra pars reticulata. This finding raised the question of whether endogenous dopamine, released from dendrites of neighboring pars compacta dopamine neurons, might act as a neuromodulator which diminishes the inhibition of pars reticulata neurons evoked by either GABA iontophoresis or electrical stimulation of the striatonigral GABAergic pathway.

Extracellular, single-unit activity of pars reticulata neurons was recorded in male rats anesthetized with chloral hydrate. In one set of studies, $d$-amphetamine, a drug reported to release dopamine from nigral dendrites, was administered intravenously $(1.6 \mathrm{mg} / \mathrm{kg})$ during regular, intermittent iontophoretic pulses of GABA. As had been previously observed with iontophoresed dopamine, i.v. amphetamine significantly lessened the inhibition of reticulata neurons produced by GABA application. This change was reflected by a decrease in GABA's inhibitory potency by $22 \%$ relative to the control level of inhibition achieved prior to amphetamine administration. Amphetamine caused no decreases in GABA's effectiveness, however, in animals that had previously received treatments that depleted or destroyed nigral dopamine stores, i.e., in rats pretreated with reserpine and $\alpha$-methyl-p-tyrosine, or in rats with 6-hydroxydopamine lesions of the nigrostriatal dopamine pathway. In a second set of experiments, amphetamine or dopamine was delivered iontophoretically while monitoring the GABA-mediated (bicucullinereversible) inhibition of reticulata neurons that can be elicited by striatal stimulation. Both iontophoretically applied amphetamine and dopamine significantly reduced the ability of striatal stimulation to inhibit reticulata cell firing for $67 \%(n=12)$ and $44 \%(n=18)$ of reticulata cells tested, respectively. For amphetamine, this attenuation was reflected by a 5 -fold increase in the number of spikes occurring during the inhibitory interval following delivery of each stimulus. These findings extend those of our previous studies by demonstrating that the dopamineGABA interaction can occur with physiological release of the two transmitters within the nigra. They further confirm the role of dopamine as a neuromodulator that can act downstream from the striatum, within the substantia nigra, to modify responses of pars reticulata output neurons to their striatonigral GABAergic innervation.

\footnotetext{
Received Apr. 8, 1985; revised July 18, 1985; accepted July 19, 1985.

We wish to thank Mr. Raymond $\mathrm{R}$. Vane for his expert technical assistance. Correspondence should be addressed to Dr. Judith R. Walters, NINCDS, Building 10-ACRF, Room 5C103, Bethesda, MD 20892.

' Current address: Pharmacology Section, College of Pharmacy and Allied Health Professions, Northeastern University, Boston, MA 02115.

Copyright $(1986$ Society for Neuroscience $0270-6474 / 86 / 010120-07 \$ 02.00 / 0$
}

The existence of dopamine in dendrites of substantia nigra pars compacta dopamine neurons was first described in 1975 by Bjorklund and Lindvall. Since their report, considerable effort has been expended in establishing that the transmitter is physiologically and pharmacologically releasable from this pool (Cheramy et al., 1981; Geffen et al., 1976; Korf et al., 1976; Nieoullon et al., 1977) and, more recently, in elucidating the physiological consequences of this release. It has long been recognized that dendritically released dopamine might exert autoregulatory influences on the dopamine neurons themselves. However, it is also conceivable that dopamine released within the nigra might influence the functions of other neuronal elements within this region. Several recent extracellular, single unit recording studies (Ruffieux and Schultz, 1980; Waszczak and Walters, 1983, 1984) have focused on this latter concern - how dopamine affects the function of the output neurons of the substantia nigra pars reticulata, a strategic region in basal ganglia information-processing and motor transmission. Anatomically, the pars reticulata lies at the junction of several intersecting neuronal pathways. It is infiltrated by a dense network of dopamine-containing dendrites (Bjorklund and Lindvall, 1975; Wilson et al., 1977), and it receives a major innervation, which is in part GABAergic, from the striatum (Fonnum et al., 1974; Kim et al., 1971). Its projections to several premotor nuclei outside the basal ganglia (Graybiel and Ragsdale, 1979) confer upon the pars reticulata the role of a strategic informationprocessing station, which receives, integrates, and transmits discrete movement-related commands to motor effector sites (Cools et al., 1983; Olianas et al., 1978; Scheel-Kruger, 1982). Thus, if release of dopamine within the ventral substantia nigra either directly influences pars reticulata neurons, or alters their responses to afferent inputs, then one physiological consequence of dendritic release would be modification of motor transmission from the basal ganglia to effector nuclei.

We recently reported that dopamine, applied by microiontophoresis, can change the baseline firing rates as well as the responses of pars reticulata neurons to iontophoretically applied GABA (Waszczak and Walters, 1983). Specifically, baseline firing rates of approximately half of all cells tested were increased by $20 \%$ or more during dopamine application. Unrelated to the increases in baseline firing rates, dopamine also markedly and consistently lessened the inhibition of reticulata cell firing elicited by GABA iontophoresis. The ability of exogenously applied dopamine to modify responses to applied GABA raises the question of whether a similar modulatory interaction between these transmitters might occur upon their endogenous release from processes within the substantia nigra. The objective of the following studies was to explore whether endogenous dopamine, released pharmacologically from dendrites of pars compacta dopamine neurons, might act as a neuromodulator that dimin- 
ishes responses of pars reticulata neurons to their striatal GABAergic innervation. In support of this hypothesis, we report here that intravenous or iontophoretically applied amphetamine, which releases dopamine from dendrites in substantia nigra (Cheramy et al., 1981; Nieoullon et al., 1977), attenuates the GABA-mediated inhibition of pars reticulata cells evoked by either GABA iontophoresis or striatal stimulation.

\section{Materials and Methods}

\section{Single-unit recording techniques}

Extracellular, single-unit activity of substantia nigra pars reticulata neurons was monitored in male Sprague-Dawley rats, $250-350 \mathrm{gm}$, which were anesthetized with chloral hydrate, $400 \mathrm{mg} / \mathrm{kg}$, i.p. Animals were mounted in a stereotaxic apparatus and a needle was inserted into a tail vein. Subsequent injections of chloral hydrate were administered intravenously, as needed. Body temperature was maintained at $36-38^{\circ} \mathrm{C}$.

The techniques for extracellular, single-unit recording and microiontophoresis were the same as described previously (Waszczak and Walters, 1983; Waszczak et al., 1980). A small burr hole was drilled in the skull at a site $2.0 \mathrm{~mm}$ lateral to the midline suture and $3.0 \mathrm{~mm}$ anterior to the lambdoid suture. An electrode was lowered through the hole to the level of the substantia nigra with a hydraulic microdrive.

All cells recorded in these studies were located in the pars reticulata region of the substantia nigra and within the following stereotaxic coordinates: $1760-2580 \mu \mathrm{m}$ anterior, $1.8-2.5 \mathrm{~mm}$ lateral, and -1.5 to $-2.5 \mathrm{~mm}$ ventral, according to the atlas of König and Klippel (1970). Identification of neurons as pars reticulata cells was made during the recording period on the basis of the following criteria: (1) location ventral to the pars compacta dopamine neurons, whose electrophysiological characteristics are easily recognized and well documented (Bunney et al., 1973; Guyenet and Aghajanian, 1978; Waszczak et al., 1980) and (2) the distinguishing electrophysiological features of pars reticulata neurons, including their smooth, sharp, biphasic action potentials of 0.5 $0.7 \mathrm{msec}$ duration and their firing rates (typically $10-40$ spikes/sec), as previously described (Guyenet and Aghajanian, 1978; Waszczak et al., 1980). Verification of correct placement of the electrode tip in the pars reticulata could be made histologically after recording experiments, as detailed below.

The electrodes used in these studies were five barrel-glass micropipettes (tip diameter, 4-6 $\mu \mathrm{m}$ ) with a central recording harrel, and four outer barrels used for iontophoretic drug delivery and current-balancing. All barrels were prefilled with glass fibers prior to pulling the pipette, in order to facilitate filling with the appropriate solutions. The central barrel was filled with $2 \mathrm{M} \mathrm{NaCl}$ which contained $1 \%$ Pontamine sky blue. One of the outer barrels was filled with $4 \mathrm{M} \mathrm{NaCl}$ and served as a balance channel. The remaining outside barrels were filled with one of the following combinations of three drug solutions: GABA $(0.001 \mathrm{~m}$ in $0.2 \mathrm{M} \mathrm{NaCl}, \mathrm{pH} 4)$, dopamine hydrochloride $(0.2 \mathrm{M}, \mathrm{pH} 4)$, and $\mathrm{NaCl}$ $(0.2 \mathrm{M})$; or dopamine hydrochloride (as above), $d$-amphetamine $(0.2 \mathrm{M}$, $\mathrm{pH} 4$ ), and bicuculline methochloride ( $5 \mathrm{~mm}$ in $165 \mathrm{~mm} \mathrm{NaCl}$ ). The impedance of the recording barrel typically ranged from 2 to $7 \mathrm{M} \Omega$, and that of the balance channel ranged from 15 to $50 \mathrm{M} \Omega$. Drug-containing barrels typically had impedances of 65-100 M $\Omega$.

\section{Studies with i.v. d-amphetamine}

In one series of experiments, the effects of intravenously administered $d$-amphetamine on responses of pars reticulata neurons to iontophoretically applied GABA were tested. For each cell, repeated $30 \mathrm{sec}$ iontophoretic pulses of GABA, separated by $30 \mathrm{sec}$ periods of baseline activity, were delivered at an ejection current sufficient to inhibit reticulata cell firing by at least $50 \%$, but not totally. After establishing a consistent response to GABA (at least three applications, yielding similar degrees of inhibition at the same ejection current), amphetamine $(1.6 \mathrm{mg} / \mathrm{kg})$ was administered i.v., and responses to GABA during the next 5-10 min interval were compared with those before amphetamine administration. The average inhibition elicited by GABA before amphetamine injection (in numbers of spikes $/ 5 \mathrm{sec}$ ) was compared with the avcrage inhibition produced by GABA after amphetamine administration for each neuron tested. In order to distinguish and separate any amphetamine-induced changes in baseline firing from amphetamine effects on GABA's inhibitory potency, we have used a method of calculation that was described in earlier reports concerning the modulatory effects of dopamine (Waszczak and Walters, 1983, 1984). This method, as applied here, involves expressing amphetamine-induced alterations in the response to GABA in terms of the change in numbers of spikes inhibited by GABA relative to the original, predrug baseline firing rate, rather than the variable, and frequently higher, rate often attained after amphetamine administration. This method of evaluation (comparing changes in absolute numbers of spikes inhibited relative to the original baseline rate) frequently imposed a more stringent criterion for determination of modulatory interactions than would comparison of percentage changes in firing based upon the original and amphetaminealtered rates. Our use of this method implies no underlying mechanism of action of amphetamine in altering responses to GABA.

The ability of i.v. amphetamine to modify responses of pars reticulata neurons to applied GABA was also evaluated in rats that had previously received treatments that depleted or destroyed nigral dopamine stores. To this end, one group of rats received reserpine $(1.5 \mathrm{mg} / \mathrm{kg}$, i.p.) $16-$ $24 \mathrm{hr}$ before the recording experiment, followed by $\alpha$-methyl-p-tyrosine methyl ester hydrochloride $(250 \mathrm{mg} / \mathrm{kg}$, i.p.), administered 2-4 hr before recording. A second group of rats received ipsilateral 6-hydroxydopamine lesions of the ascending nigral dopaminergic neurons $1-4$ weeks prior to the recording experiment. To test for the previously reported modulatory response to applied dopamine, iontophoresis of the transmitter was initiated from 8-10 min after the amphetamine injection and was continued for a 3-5 min period.

At the end of recording experiments, a small amount of Pontamine blue dye was iontophoretically deposited in the brain by passing a 15 $\mu \mathrm{A}$ current through the recording barrel of the electrode for approximately $15 \mathrm{~min}$. The animal was then decapitated and the brain removed, fixed, sectioned, mounted, and stained. The location of a blue spot within the pars reticulata verified correct placement of the electrode during the recording period. In all studies where rats received i.v. amphetamine injections, only one cell was monitored after the drug injection.

\section{6-Hydroxydopamine lesion technique}

Unilateral 6-hydroxydopamine lesions were placed in the left nigrostriatal pathway at a location just anterior to the substantia nigra, as described previously (Waszczak et al., 1984b). Lesioned animals were used in recording studies 1-4 weeks after 6-hydroxydopamine injections. After recording experiments, striata were removed and rapidly frozen to $-60^{\circ} \mathrm{C}$. Dopamine levels were later determined in the left and right striata of each rat by high-pressure liquid chromatography with electrochemical detection, according to the method of Wagner et al. (1982). Animals were excluded from the study if dopamine levels in the lesioned striatum exceeded $10 \%$ of those on the unlesioned side.

\section{Striatal-stimulation studies}

A second series of studies was conducted to determine the effects of iontophoretically applied dopamine, $d$-amphetamine, and bicuculline methochloride on the inhibition of reticulata cell firing elicited by striatal stimulation. Stimuli consisted of square pulses, $100-300 \mu \mathrm{A}$ in intensity and $300 \mu \mathrm{sec}$ in duration, which were delivered at a frequency of $1 \mathrm{~Hz}$ for $1 \mathrm{~min}$ to the left striatum, ipsilateral to the recording site, through a $2 \times 2$ array of four elcctrodes (approximately $2 \mathrm{~mm}$ tip separation; insulated to within $0.5 \mathrm{~mm}$ of the tips). The four electrodes were stereotaxically positioned at 2.0 and $4.0 \mathrm{~mm}$ lateral, 9.0 and 11.0 $\mathrm{mm}$ anterior, and between 3 and $6 \mathrm{~mm}$ ventral. Stimuli were applied to three electrodes and returned through the fourth.

Poststimulus time histogram plots ( $1 \mathrm{msec} / \mathrm{bin})$ of the effects of striatal stimulation on pars reticulata cell firing were constructed using a Medical Systems Corp. Neurograph Model STA-1 signal analyzer/averager. Corresponding oscilloscope traces of neuronal activity during $1 \mathrm{~min}$ periods of stimulation were also stored and photographed. After completion of at least three control poststimulus time histograms, dopamine ( $10 \mathrm{nA}$ ejection current), $d$-amphetamine (5-10 $\mathrm{nA}$ ejection current), and bicuculline methochloride (5-20 nA ejection current) were applied in turn by microiontophoresis for a period of 8-10 min each. During application of each drug, poststimulus time histograms and oscilloscope records were obtained for at least three 1 min periods of striatal stimulation. Between drug applications, sufficient time was allowed for the inhibitory response to striatal stimulation to recover to approximately that of the control period, recorded before drug application. Values for the average number of spikes that occurred during the prefixed (control) inhibitory interval were then determined for the histograms generated during drug applications. Drug-induced changes in the inhibitory response to striatal stimulation were calculated by comparing the number 

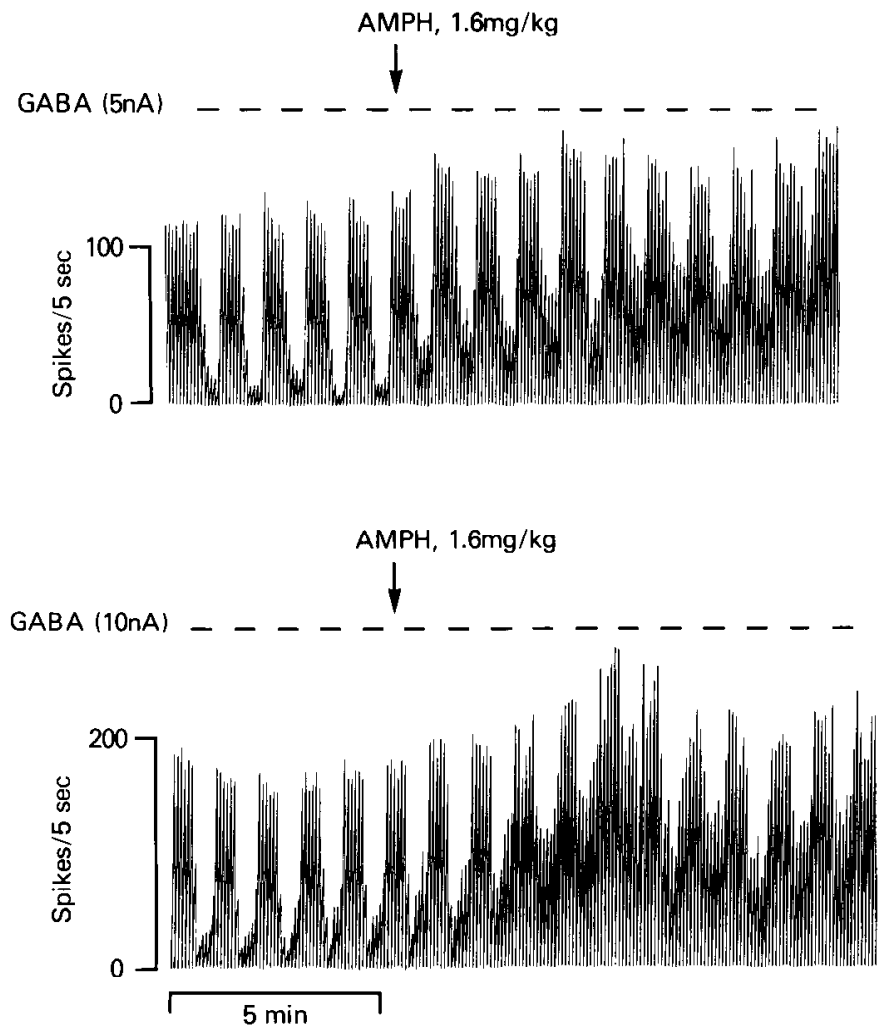

Figure 1. Ratemeter recording of the effects of i.v. administration of $d$-amphetamine $(A M P H)$ on responses of substantia nigra pars reticulata neurons to iontophoretically applied GABA. Although amphethamine had variable effects on baseline firing rates of some neurons, it significantly reduced the inhibitory responses of many cells to iontophoretically applied GABA.

of spikes/msec during the control inhibitory period with the number of spikes/msec during periods of drug application. Statistical significance $(p<0.05)$ of such changes was determined by Student's $t$ test.

In striatal-stimulation experiments, frequently more than one cell was monitored per rat. The electrode position for the last neuron was marked by ejection of Pontamine blue dye. Verification of correct placement of the electrode for previously recorded neurons was made by reconstructing their location from stereotaxic coordinates and histological examination of sections.

\section{Results}

Effects of i.v. amphetamine on responses of pars reticulata neurons to iontophoretically applied $G A B A$

Intravenous administration of $d$-amphetamine $(1.6 \mathrm{mg} / \mathrm{kg})$ was able to reduce responses of reticulata neurons to applied GABA in animals with intact nigral dopaminergic systems. The response to amphetamine (Fig. 1), which was presumably due to release of dopamine from nearby dendrites, was consistent with and similar to the previously reported (Waszczak and Walters, 1983,1984 ) attenuation of reticulata responses to GABA observed during dopamine application (Fig. 2). When the responses of all cells tested were considered together, amphetamine was found to have caused a significant reduction in GABA's inhibitory potency. This reduction was reflected by an decrease in the number of spikes inhibited by GABA before, versus after, amphetamine administration. During the predrug trials, GABA caused an average inhibition of reticulata cell firing of $70.5 \pm 2.7 \%$, while after amphetamine injection, the ability of GABA to inhibit firing was reduccd to a valuc of $54.9 \pm 4.5 \%$ of the original baseline firing rates. Thus, the overall difference between the degree of inhibition achieved by GABA

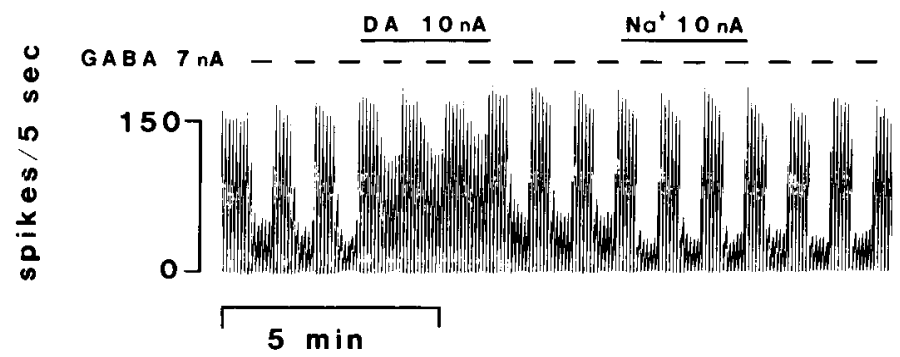

Figure 2. Effects of iontophoretically applied dopamine $(D A ; 0.2 \mathrm{м}$, $\mathrm{pH} 4$ ) on the inhibition of a substantia nigra pars reticulata neuron by iontophoretically applied GABA. Dopamine, but not an equimolar solution of $\mathrm{NaCl}$, attenuated the inhibitory responses to applied GABA, as previously reported (Waszczak and Walters, 1983, 1984).

before, compared with after, amphetamine administration averaged $15.6 \pm 3.7 \%$ of the baseline rates $(n=15 ; p<0.001$ by paired Student's $t$ test). This difference represents a net decrease in GABA's potency by $22 \%$ relative to the control levels of inhibition achieved prior to amphetamine administration.

In a parallel series of experiments, in which rats had been pretreated with reserpine and $\alpha$-methyl-p-tyrosine, or had previously received 6-hydroxydopamine lesions, i.v. amphetamine did not diminish responses of pars reticulata neurons to GABA. In the reserpine- and $\alpha$-methyl- $p$-tyrosine-pretreated rats (Fig. 3), GABA inhibition of reticulata cell firing averaged $73.6 \pm$ $5.2 \%$ in the control trials before amphetamine injection. Following amphetamine administration, GABA inhibited firing by $86.2 \pm 8.6 \%$ of the original baseline firing rates $(n=7)$. This change represents a slight, nonsignificant increase in GABA's inhibitory potency, rather than the customary attenuation of GABA responses observed in animals not depleted of nigral dopamine. Similarly, in rats that received 6-hydroxydopamine lesions 1-4 weeks before the recording experiment, responses to GABA were slightly, but not significantly, potentiated after amphetamine treatment (Fig. 4). In these animals, GABA inhibited firing by $78.9 \pm 3.5 \%$ before amphetamine, and by $94.6 \pm 10.8 \%$ after amphetamine administration $(n=12)$. Thus, in those situations in which dopamine stores were depleted, either pharmacologically or by lesions of the nigrostriatal dopamine neurons, amphetamine failed to lessen responses of pars reticulata neurons to iontophoretically applied GABA.

In both groups of dopamine-depleted rats, i.e., those pretreated with reserpine and $\alpha$-methyl-p-tyrosine and those with 6hydroxydopamine lesions, iontophoretically applied dopamine retained its ability to reduce responses to applied GABA (Figs. 3 and 4) despite the inability of i.v. amphetamine to do so. In fact, in animals lesioned with 6-hydroxydopamine 5-6 weeks prior to recording experiments, iontophoresed dopamine has been found to cause a significantly greater attenuation of GABA's effects than in unlesioned control rats (Waszczak and Walters, 1984).

\section{Effects of iontophoretically applied amphetamine and dopamine on GABA-mediated inhibition of pars reticulata neurons evoked by striatal stimulation}

These studies assessed the ability of both iontophoresed dopamine and amphetamine to modify the GABA-mediated inhibition of pars reticulata neurons that can be readily elicited by striatal stimulation. Poststimulus time histogram plots, constructed during 1 min periods of striatal stimulation at $1 \mathrm{~Hz}$, revealed that firing of reticulata neurons was inhibited after a short latency (average, $8.2 \pm 0.8 \mathrm{msec}$ ) and for a discrete interval (average, $26.0 \pm 5.0 \mathrm{msec}$ ) following delivery of each stimulus. This inhibitory response to striatal stimulation could be attributed to activation of striatonigral GABA pathways, since it could be reduced by iontophoresis of the GABA antagonist, bicucul- 


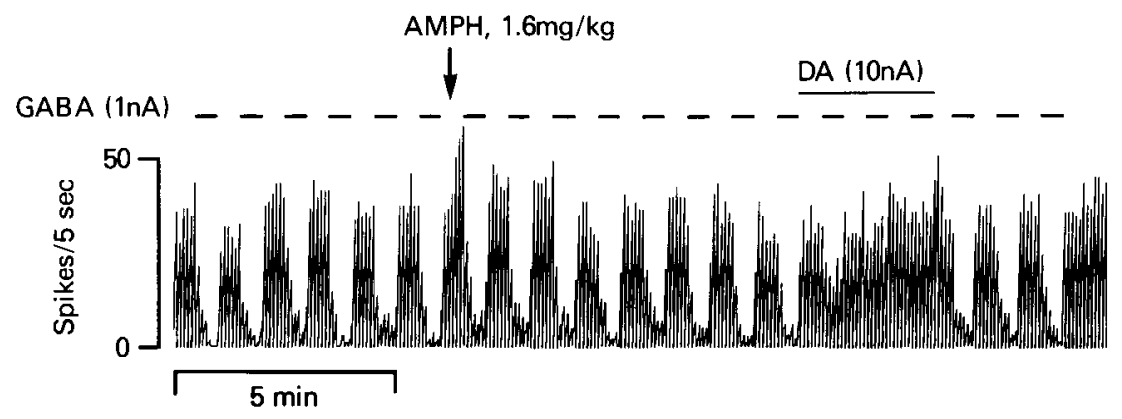

Figure 3. In rats pretreated with reserpine and $\alpha$-methyl- $p$-tyrosine, i.v. $d$-amphetamine $(A M P H)$ failed to reduce responses of pars reticulata neurons to iontophoretically applied GABA. Despite the inability of amphetamine to do so, iontophoretically applied dopamine $(D A)$ retained its customary ability to lessen responses to GABA.

line methochloride (5-20 nA ejecting current; Fig. 5). In addition to this consistently observed, short-latency inhibition of firing, striatal stimulation also occasionally evoked short-latency excitatory responses, as evidenced in Figure 5. However, our evaluation of how dopamine or amphetamine modified responses to striatal stimulation was restricted, during this study, only to the analysis of how these drugs altered the bicuculline-sensitive, striatal-evoked inhibitions of reticulata cell-firing. Limiting the scope of our analysis in this manner is not intended to imply either an ability or inability of dopamine to alter excitatory responses to striatal stimulation.

Iontophoresed dopamine significantly $(p<0.05)$ reduced the ability of striatal stimulation to inhibit pars reticulata cell firing for 8 out of 18 cells (44\%) tested (Fig. 5). This attenuation by applied dopamine was reflected by a 10 -fold increase in the number of spikes occurring/msec bin during the previously defined inhibitory interval (established during control periods, when striatal stimulation was carried out prior to dopamine application). The number of spikes/msec during the control inhibitory period (before dopamine application) averaged $0.05 \pm 0.02$, whereas this value increased to $0.5 \pm 0.11 \mathrm{spikes} / \mathrm{msec}$ during dopamine iontophoresis. When dopamine application was terminated, the inhibitory response to striatal stimulation typically recovered within several minutes (Fig. 5).

In testing the abilty of iontophoretically applied amphetamine to modify the inhibitory responses of reticulata cells to striatal stimulation, a similar attenuating effect was observed. Amphetamine, ejected with 5-10 nA currents, significantly $(p<$ 0.05 ) reduced the striatal-evoked inhibition of 8 out of 12 neurons (67\%) studied (Fig. 5). This attenuation was reflected by a 5 -fold increase in the number of spikes occurring during the predefined inhibitory interval: from $0.11 \pm 0.05$ spikes $/ \mathrm{msec}$ in the control periods to $0.57 \pm 0.11$ spikes $/ \mathrm{msec}$ during amphetamine iontophoresis. As before, when amphetamine delivery was discontinued, the inhibitory response to striatal stimulation returned within several minutes.

\section{Discussion}

Previous electrophysiological studies from this laboratory demonstrated an ability of iontophoretically applied dopamine to attenuate the inhibitory effects of iontophoresed GABA on rat substantia nigra pars reticulata neurons (Waszczak and Walters, 1983). In those initial studies, both dopamine and GABA were applied by iontophoresis to simulate endogenous conditions under which the two transmitters might possibly interact. The current experiments were directed toward establishing whether the reported dopamine-GABA interaction could occur when the two transmitters were released from endogenous storage sites within the substantia nigra pars reticulata, i.e., from dopaminecontaining dendrites and GABAergic striatonigral terminals. In support of this possibility, numerous previous reports have verified that dopamine is physiologically and pharmacologically releasable, in vivo and in vitro, from dendrites within the pars reticulata. Release has been shown to be induced by electrical stimulation (Korf et al., 1976), intranigral infusions of veratridine (Tagerud and Cuello, 1979) or potassium (Cheramy et al., 1981 ), or by $d$-amphetamine, an indirectly acting sympathomimetic drug (Cheramy et al., 1981; Nieoullon et al., 1977). In addition, pars reticulata neurons have been shown to be contacted by GABAergic terminals of striatonigral neurons (Oertel et al., 1982). Electrical stimulation of this striatonigral pathway has been reported to elicit a short-latency, monosynaptic inhibition of reticulata cell firing that can be blocked by iontophoretic application of bicuculline, a GABA antagonist (Collingridge and Davies, 1981).

In these studies, amphetamine was used as a tool for stimulating release of dopamine from nigral dendrites, and striatal stimulation was used as a means of eliciting a GABA-mediated inhibition of reticulata cell firing. Amphetamine, either administered intravenously or applied iontophoretically, modified responses of reticulata neurons to GABA in a manner consistent with our previously reported findings (Waszczak and Walters, 1983). First, i.v. amphetamine, like iontophoretically applied dopamine, reduced responses to applied GABA. In view of the fact that amphetamine was unable to attenuate GABA's effects in animals that had previously received treatments known to deplete or destroy nigral dopamine stores, the attenuation observed in normal animals was most likely attributable to an amphetamine-induced release of dopamine from dendrites near the reticulata neurons being monitored. Second, when amphet-

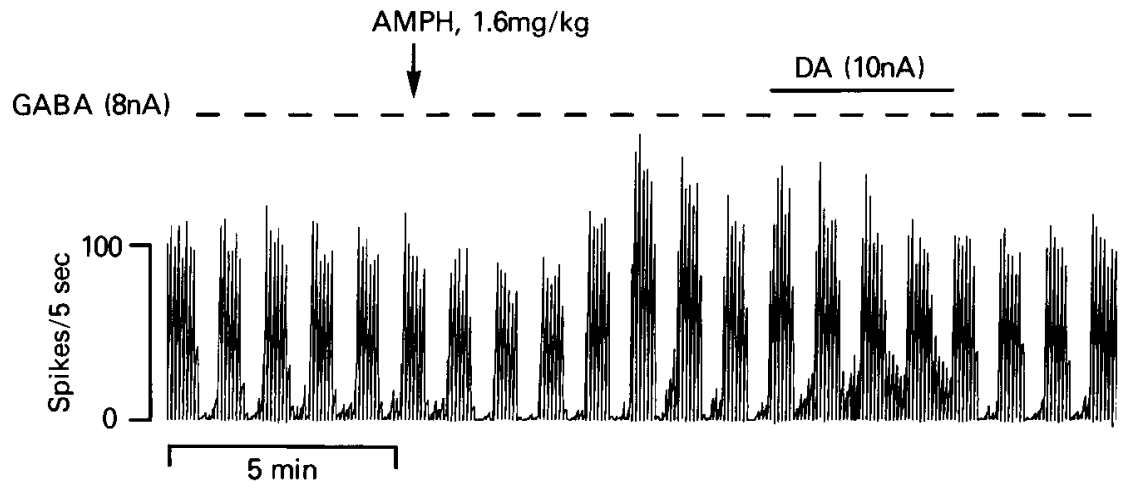

Figure 4. In rats that had previously received ipsilateral 6-hydroxydopamine lesions of the nigrostriatal dopamine neurons, i.v. $d$-amphetamine (AMPH) failed to attenuate responses of pars reticulata neurons to iontophoretically applied GABA. Dopamine $(D A)$, applied by iontophoresis, retained its customary ability to reduce responses to GABA. 
STORED OSCILLOSCOPE TRACES

(60 Sweeps)

\section{Control}

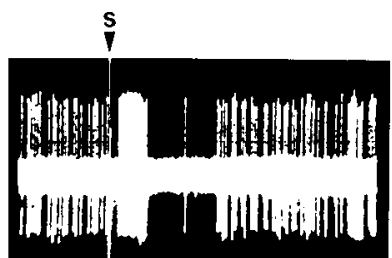

During DA lontophoresis

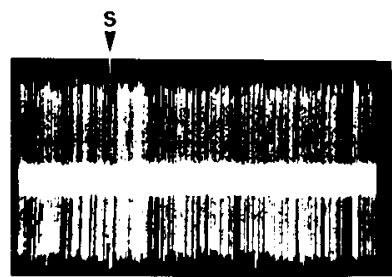

Recovery after DA

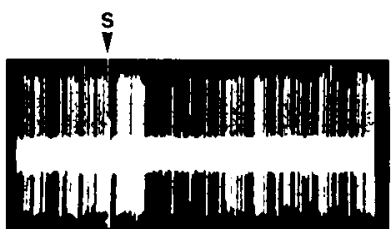

During AMPH lontophoresis

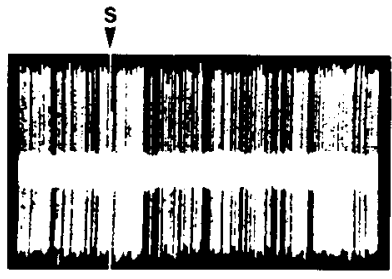

Recovery after AMPH

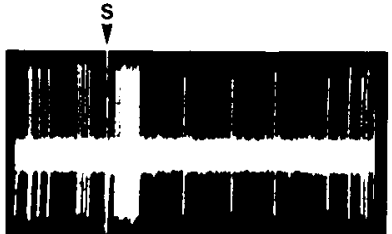

During BIC-MeCl lontophoresis

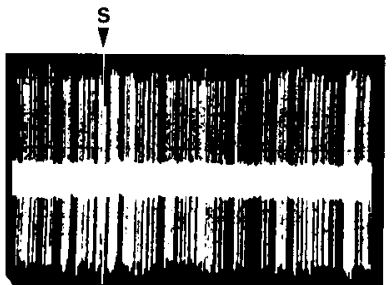

Recovery after BIC-MeCl

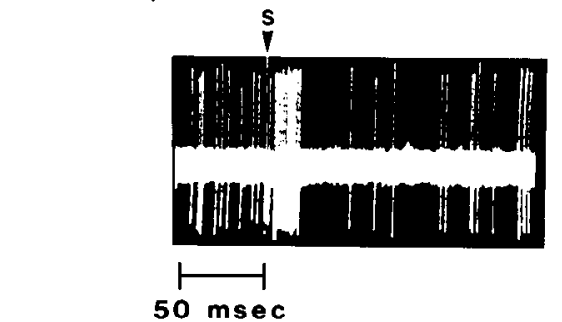

50 msec
POST STIMULUS TIME HISTOGRAMS
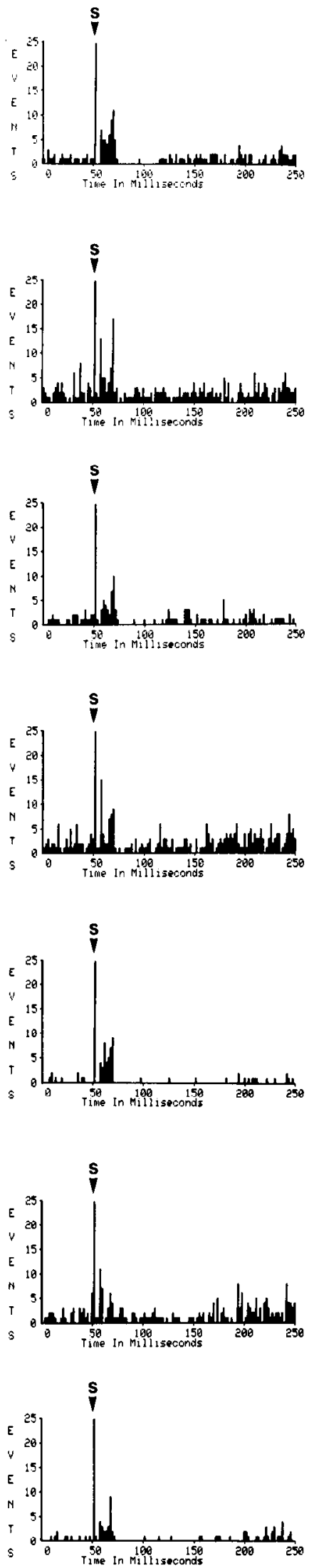
a $1 \mathrm{~min}$ period of striatal stimulation at $1 \mathrm{~Hz}$.

Figure 5. Effects of iontophoretically applied dopamine $(D A), d$-am( $(A M P H)$, and bicuculline hibition of pars reticulata cell firing evoked by striatal stimulation. Stimcaused a short-latency inhibresponse which was, for this exted by a short-latency each drug lessened the stimulusevoked inhibition of firing. Shown are stored oscilloscope traces (left) and corresponding poststimulus time his- 
amine was iontophoretically applied in the vicinity of pars reticulata neurons, the majority of these cells exhibited a significantly diminished inhibitory response to striatal stimulation. Since it was possible to reduce or abolish the striatal-evoked inhibitions of firing by iontophoretic application of the GABA antagonist, bicuculline methochloride, our results suggest that the inhibitory responses to striatal stimulation were mediated by endogenously released GABA, and that their attenuation by applied amphetamine was mediated by endogenously released dopamine. Thus, for more than half of reticulata cells tested, we could demonstrate that the dopamine-GABA interaction occurred even under experimental conditions in which dopamine relcase was presumably restricted to dendrites within the circumference of amphetamine's diffusion from the pipette tip, and that GABA release onto the cell presumably had to occur from striatonigral terminals also located within the sphere of amphetamine's diffusion and dopamine release.

In addition to the evidence cited here, we have previously reported other findings that support the conclusion that dopamine's attenuation of reticulata responses to GABA occurs physiologically. Specifically, reticulata neurons studied in rats given 6-hydroxydopamine lesions of nigral dopamine neurons 5-6 weeks earlier exhibited a greater sensitivity to dopamine's apparent "modulatory" effect than did cells from unlesioned rats (Waszczak and Walters, 1984). This development of supersensitivity to the GABA-attenuating action of dopamine, together with the current results, supports the view that the interaction between dopamine and GABA can and does occur to a physiologically relevant degree within the pars reticulata.

Several other investigators have reported data consistent with the apparent neuromodulatory role of dopamine described here. In two recent studies, dopamine was found to attenuate responses to GABA in other nuclei of the basal ganglia. For instance, comparable extracellular recording studies carried out in this laboratoryy revealed that applied dopamine reduces responses of globus pallidus neurons to iontophoresed GABA (Bergstrom and Walters, 1984). Similarly, Bernardi and coworkers (1984) described an ability of iontophoretically applied dopamine to reduce both the membrane hyperpolarization and inhibition of firing caused by iontophoresis of GABA onto striatal neurons, recorded intracellularly. In addition to the above studies, which closely parallel the current investigation, several earlier reports might now be reinterpreted as possible examples of dopamine-mediated modulation of responses to GABA. One study, by Gonzalez-Vegas and Pardey (1979), described an ability of iontophoresed dopamine to lessen the inhibition of nigral neurons, presumably pars reticulata neurons, elicited by stimulation of the globus pallidus. Another report, by Fisher et al. (1982), described an ability of i.p. amphetamine to diminish inhibitory responses of nigral neurons, including pars reticulata cells, to caudate stimulation. In both of these cases, electrical stimulation evoked an inhibition of reticulata neurons, possibly mediated by GABA, which was diminished or blocked by dopamine iontophoresis or amphetamine administration.

Thus, the results of this and previous studies strongly suggest that dopamine can act as a neuromodulator at several sites within the CNS. The term "neuromodulator" is used here to describe the apparent ability of dopamine to modify responsiveness of neurons to a second transmitter, i.e., GABA. Other monoamine transmitters, including serotonin (McCall and Aghajanian, 1979) and norepinephrine (Moises et al., 1979, 1981; Rogawski and Aghajanian, 1980; Waterhouse et al., 1980) have been shown by similar techniques to act as neuromodulators at other sites in the brain. While our findings bring to light a potentially important functional interaction between dopamine and GABA within the substantia nigra, they do not elucidate the mechanism underlying this interaction. Whether the transmitters interact at the receptor level, or through an ionic mechanism at the membrane level, remains to be revealed. The significance of these findings with regard to basal ganglia information-processing and transmission are considerable. Dopamine's ability to lessen responses of pars reticulata neurons to their striatonigral GABAergic innervation may constitute an important and previously unrecognized mechanism by which nigral dopamine neurons regulate basal ganglia output function without directly involving the striatum. In fact, deciphering how dopamine ultimately influences pars reticulata output function will now require recognition of both its indirect, striatally mediated effects as well as its local, direct effects on reticulata cell activity. Indeed, extending the range of dopamine's functions to include its direct, GABA-attenuating effects may help to resolve certain discrepancies that have already developed in the literature with regard to the net effect of dopamine on basal ganglia output transmission. For instance, it is widely believed that activation of striatal dopamine receptors, as produced by systemic administration of drugs like apomorphine, causes an inhibition of substantia nigra output function, presumably mediated by activation of striatonigral GABAergic pathways to reticulata neurons (Childs and Gale, 1983; DiChiara et al., 1978; Kilpatrick et al., 1982; Olianas et al., 1978; Reavill et al., 1981; Redgrave et al., 1980; Scheel-Kruger, 1982). However, singleunit recording studies of the effects of i.v. apomorphine on reticulata neurons revealed that these neurons are quite variably affected by the drug: $34 \%$ of the cells studied exhibited increases in firing; $43 \%$ exhibited no changes in rate; and only $23 \%$ displayed decreases in firing rate (Waszczak et al., 1984a, b). One explanation for the variable responses of reticulata neurons to apomorphine might be a variable balance achieved between inhibitory, striatally mediated effects of the drug and its "disinhibitory" (GABA-attenuating) effects, which occur locally within the pars reticulata.

In recent years, the substantia nigra pars reticulata has gained acceptance as a critical motor output center, which both receives, and then transmits, striatal movement-related commands to premotor nuclei outside the basal ganglia. Discovery of a new role for dopamine as a "modulator" of this transmission process should now reshape and enlarge our view of the pars reticulata beyond that of a simple relay center, to include integrative and "gain-adjusting" functions as well.

\section{References}

Bergstrom, D. A., and J. R. Walters. (1984) Dopamine attenuates the effects of GABA on single unit activity in the globus pallidus. Brain Res. 310: 23-33.

Bernardi, G., P. Calabresi, N. Mercuri, and P. Stanzione (1984) Evidence for a neuromodulatory role of dopamine in rat striatal neurons. Clin. Neuropharmacol. 7 (Suppl. 1): 66-67.

Bjorklund, A., and O. Lindvall (1975) Dopamine in dendrites of substantia nigra neurons: Suggestions for a role in dendritic terminals. Brain Res. 83: 531-537.

Bunney, B. S., J. R. Walters, R. H. Roth, and G. K. Aghajanian (1973) Dopaminergic neurons: Effect of antipsychotic drugs and amphetamine on single cell activity. J. Pharmacol. Exp. Ther. 185: 560-571.

Cheramy, A., V. Leviel, and J. Glowinski (1981) Dendritic release of dopamine in the substantia nigra. Nature 289: 537-542.

Childs, J. A., and K. Gale (1983) Evidence that the nigrotegmental GABAergic projection mediates stereotypy induced by apomorphine and intranigral muscimol. Life Sci. 33: 1007-1010.

Collingridge, G. L., and J. Davies (1981) The influence of striatal stimulation and putative neurotransmitters on identified neurons in the rat substantia nigra. Brain Res. 212: 345-359.

Cools, A. R., R. Jaspers, W. Kolasiewicz, K.-H. Sontag, and S. Wolfarth (1983) Substantia nigra as a station that not only transmits, but also transforms, incoming signals for its behavioural expression: Striatal dopamine and GABA-mediated responses of pars reticulata neurons. Behav. Brain Res. 7: 39-51

DiChiara, G., M. Morelli, M. L. Porceddu, and G. L. Gessa (1978) Evidence that nigral GABA mediates behavioural responses elicited by striatal dopamine receptor stimulation. Life Sci. 23: 2045-2052. 
Fisher, R. S., M. S. Levine, C. D. Hull, and N. A. Buchwald (1982) Amphetamine alters evoked responses of nigral neurons in kittens and adult cats. Brain Res. 237: 415-427.

Fonnum, F., I. Grofova, E. Rinvik, J. Storm-Mathisen, and F. Walberg (1974) Origin and distribution of glutamate decarboxylase in substantia nigra of the cat. Brain Res. 71: 77-92.

Geffen, L. B., T. M. Jessell, A. C. Cuello, and L. L. Iversen (1976) Release of dopamine from dendrites in rat substantia nigra. Nature 260: 258-260.

Gonzalez-Vegas, J. A., and B. Pardey (1979) A presynaptic action of dopamine on globus pallidus afferents to substantia nigra in the rat. Neurosci. Lett. 14: 77-80.

Graybiel, A. M., and C. W. Ragsdale (1979) Fiber connections of the basal ganglia. Prog. Brain Res. 51: 239-283.

Guyenet, P. G., and G. K. Aghajanian (1978) Antidromic identification of dopaminergic and other output neurons of the rat substantia nigra. Brain Res. 150: 69-84.

Kilpatrick, I. C., G. L. Collingridge, and M. S. Starr (1982) Evidence for the participation of nigrotectal gamma-aminobutyrate-containing neurones in striatal and nigral-derived circling in the rat. Neuroscience 7: 207-222

Kim, J. S., I. J. Bak, R. Hassler, and Y. Okada (1971) Role of $\gamma$-aminobutyric acid (GABA) in the extrapyramidal motor system. 2. Some evidence for the existence of a type of GABA rich strionigral neurons. Exp. Brain Res. 14: 95-104.

König, J. F. R., and R. A. Klippel (1970) The Rat Brain: A Stereotaxic Atlas, R. E. Krieger, Huntington, NY.

Korf, J., M. Zieleman, and B. H. C. Westerink (1976) Dopamine release in substantia nigra. Nature 260: 257-258.

McCall, R. B., and G. K. Aghajanian (1979) Serotonergic facilitation of facial motoneuron excitation. Brain Res. 169: 11-27.

Moises, H. C., B. D. Waterhouse, and D. J. Woodward (1981) Locus coeruleus stimulation potentiates Purkinje cell responses to afferent input: The climbing fiber systcm. Brain Res. 222: 43-64.

Moises, H. C., D. J. Woodward, B. J. Hoffer, and R. Freeman (1979) Interactions of norepinephrine with Purkinje cell responses to putative amino acid neurotransmitters applied by microiontophoresis. Exp. Neurol. 64: 493-515.

Nieoullon, A., A. Cheramy, and J. Glowinski (1977) Release of dopamine in vivo from cat substantia nigra. Nature 266: 375-377.

Oertel, W. H., M. L. Tappaz, A. Berod, and E. Mugnaini (1982) Twocolor immunohistochemistry for dopamine and GABA neurons in rat substantia nigra and zona incerta. Brain Res. Bull. 9: 463-474.

Olianas, M. C., G. M. de Montis, G. Mulas, and A. Tagliamonte (1978) The striatal dopaminergic function is mediated by the inhibition of a nigral, non-dopaminergic neuronal system via a strio-nigral GABAergic pathway. Eur. J. Pharmacol. 49: 233-241.

Reavill, C., P. Jenner, N. Leigh, and C. D. Marsden (1981) The role of nigral projections to the thalamus in drug-induced circling behavior in the rat. Life Sci. 28 : 1457-1466.
Redgrave, P., P. Dean, T. P. Donohue, and S. G. Pope (1980) Superior colliculus lesions selectively attenuate apomorphine-induced oral stereotypy; a possible role for the nigrotectal pathway. Brain Res. 197: 541-546.

Rogawski, M. A., and G. K. Aghajanian (1980) Modulation of lateral geniculatc ncuronc excitability by noradrenalinc microiontophoresis or locus coeruleus stimulation. Nature 287: 731-733.

Ruffieux, A., and W. Schultz (1980) Dopaminergic activation of reticulata neurones in the substantia nigra. Nature 285: 240-241.

Scheel-Kruger, J. (1982) GABA: An essential moderator and mediator in the basal ganglia system of dopamine related functions. Acta Neurol. Scand. 65 (Suppl.) 90: 40-45.

Tagerud, S. E. O., and A. C. Cuello (1979) Dopamine release from the rat substantia nigra in vitro. Effect of raphe lesions and veratridine stimulation. Neuroscience 4: 2021-2029.

Wagner, J., P. Vitali, M. G. Palfreyman, M. Zraika, and S. Huot (1982) Simultaneous determination of 3,4-dihydroxyphenylalanine,5-hydroxytryptophan, dopamine, 4-hydroxy-3-methoxyphenylalanine, norepinephrine, 3,4-dihydroxyphenylacetic acid, homovanillic acid, scrotonin, and 5-hydroxyindolcacctic acid in rat ccrcbrospinal fluid and brain by high-performance liquid chromatography with electrochemical detection. J. Neurochem. 38: 1241-1254.

Waszczak, B. L., and J. R. Walters (1983) Dopamine modulation of the effects of $\gamma$-aminobutyric acid on substantia nigra pars reticulata neurons. Science 220: 218-221.

Waszczak, B. L., and J. R. Walters (1984) A physiological role for dopamine as modulator of GABA effects in substantia nigra: Supersensitivity in 6-hydroxydopamine lesioned rats. Eur. J. Pharmacol. 105: 369-373.

Waszczak, B. L., N. Eng, and J. R. Walters (1980) Effects of muscimol and picrotoxin on single unit activity of substantia nigra neurons. Brain Res. 188: 185-197.

Waszczak, B. L., E. K. Lee, T. Ferraro, T. A. Hare, and J. R. Walters (1984a) Single unit responses of substantia nigra pars reticulata neurons to apomorphine: Effects of striatal lesions and anesthesia. Brain Res. 306: 307-318.

Waszczak, B. L., E. K. Lee, C. A. Tamminga, and J. R. Walters (1984b) Effect of dopamine system activation on substantia nigra pars reticulata output neurons: Variable single-unit responses in normal rats and inhibition in 6-hydroxydopamine-lesioned rats. J. Neurosci. 4: 2369-2375.

Waterhouse, B. D., H. C. Moises, and D. J. Woodward (1980) Noradrenergic modulation of somatosensory cortical neuronal responses to iontophoretically applied putative neurotransmitters. Exp. Neurol. 69: $30-49$

Wilson, C. J., P. M. Groves, and E. Fifkova (1977) Monoaminergic synapses including dendrodendritic synapses in the rat substantia nigra. Exp. Brain Res. 30: 161-174. 